\title{
Meaning and Entrainment in Language and Music Special Issue: Introduction
}

\author{
FABIA FRANCO \\ Department of Psychology, Middlesex University, UK \\ IAN CROSS \\ Centre for Music \& Science, University of Cambridge, UK
}

THE relationship between music and language has been a fast-growing field of scientific investigation in the last fifteen years or so, but their intersections, overlappings and relative prominence have been at the heart of much debate also historically. In the West, since Salieri's "Prima la musica e poi le parole" (1786) through to Strauss' "Capriccio" (1942) questions have been playfully put from within the musical domain concerning the genetic relationship between language and music in art, while Darwin had speculated that vocalisation, particularly rudimentary song was the root of language: “...the rhythms and cadences of oratory are derived from previously developed musical powers........... Musical sounds afforded one of the bases for the development of language" (1871, p. 336). More recently, in 1995 Diana Deutsch has identified an intriguing perceptual illusion that illustrates deep interrelationships between spoken language and music ('speech-to-song' - see Deutsch, Henthorn \& Lapidis, 2011), questioning the separability of the two at any obvious empirical level. Thus, one might be tempted into a new reading of John Blacking's famous definition of music as "humanly organized sound" (Blacking, 1976: 26), extending beyond music to embrace spoken language too.

The attempts to describe language and music in terms of their similarities and differences have been numerous and illustrious, spanning from functional to structural aspects. Universally present across human cultures, language and music are complex systems in which communication is based primarily on sound (although other senses, gesture and the motor system are involved) and in which specific brain disorders exist that affect both perception and production as in aphasia and amusia. Both systems involve the development of literacy based on specific alphabets and orthographies, notation systems and scales, which are, in turn, rooted in particular structures grouping subordinate elements according to rules that are largely (but not exclusively) culture-specific. However, scholars do not necessarily agree when debating on the degree to which language and music are to be considered as two specializations derived from the same system, or two distinct systems - for reviews, see Rebuschat, Rohrmeier, Hawkins \& Cross, 2012; Slevc 2012.

Questions have continued to unfold from more and more diverse disciplines, in an attempt to explore and define the boundaries between the two main human communicative systems, creating what is an intrinsically interdisciplinary field allying psychology, musicology, linguistics, neuroscience, artificial intelligence, anthropology, philosophy, evolutionary biology and movement sciences.

The present double special issue of Empirical Musicology Review collects papers that were presented in one of a series of three interdisciplinary seminars and workshops sponsored by the British Psychological Society, dedicated to the relationship between language and music. The first seminar took place in London (UK), in July 2010, and was dedicated to exploring how the complementary study of phylogenesis and cultures in one respect, and ontogenesis in another, may contribute to the debate with strands in Evolution and Development in human infants and children (Franco, Brunswick \& de MornayDavies, 2010). The second seminar took place in Cambridge (UK), in December 2010, tackling directly two aspects that lie at the core of the debate on language and music, namely what seems to separate them the most: on the one hand, the kind of meaning formed and communicated in each domain, with language affording a wider variety of meanings including propositionality, but on the other hand, music affording unique specializations to entrain and align interindividual states and motor behaviours (Cross \& Woodruff, 2009). Finally, the third meeting took place in London (UK) again, in September 2011, and discussed the relationship between language and music considering Literacy and Communicative Interaction aspects [1]. Some seminars have involved more informal presentations with research ideas and multi-disciplinary brainstorming in a workshop setting - the present special issue collects the contributions emerged from the more formally structured meeting on Meaning and Entrainment.

In this meeting, five target articles, or "orientation papers", were commissioned from experts so as to provide introductions to their specific fields for reserchers in other domains. Two respondents were then asked to provide commentaries on each target article, each of the five sessions in which the papers were 
presented being conceived of as a discussion and debate between experts providing an authoritative and comprehensive overview of a specific topic. The five topics selected were: Rhythm and time in music; Rhythm and time in language; Entrainment; Meaning; and Meaning in culture. Respondents were free to direct their response towards the orientation paper of their session or completely to disregard it; most chose to produce responses that refer not only to "their own" orientation paper but also to others, highlighting the extent to which the selected themes exhibit commonalities across the domains of music and language.

In his target article Rhythm and Time in Music, Justin London identifies and illustrates three key aspects: that metre and grouping are distinct from one another; that our experience of patterns of events in time as musical rhythm involves active, constructive processes; and that that patterns of events in time will have different perceptual and cognitive consequences that depend on their time-scales. Katie Overy endorses the informativeness of London's three aspects for an understanding of collective and communicative behaviours, and poses the question of whether the different timescales that he adduces may reflect the operation of different networks in the brain. Peter Keller's substantial response builds on London's key points in developing their significance for an understanding of the dynamics of communicative interaction in general, not just for linguists but also for those scientists concerned to explore and explain "the communication of meaning and aesthetic experience in verbal and nonverbal domains".

In Rhythm and Time in Language, Fred Cummins reviews ways in which time and rhythm have been conceptualised and explored in the study of language, suggesting that the explanatory scope of many of the frameworks and metrics proposed are undermined by assumptions of isochrony; he proposes instead that exploring the common experience of embodied movement in communicative contexts may provide a better means of understanding rhythm in speech. Roger Moore's computationally-grounded response to Cummins (and to London) suggests that rhythm and entrainment can be understood as intrinsic to, and evolutionarily adaptive for, the management of behaviour and communication, and that a general theoretical framework can be derived from energetics and information theory that can provide appropriate tools for analysing and characterising such behaviours. David House's response considers how, why, and what features of, rhythm in speech should be taken as appropriate measures, and proceeds to review the roles of tonal and durational features before noting the need to account for the role of gesture in understanding the experience of speech rhythm.

In Entrainment, Martin Clayton provides an overview of the significance of the concept of entrainment for understanding human behaviour in general and music in particular, before sketching an approach to identifying and quantifying entrainment in a range of interactive musical contexts. Usha Goswami notes that critical information in both speech and music appear to share a temporal range, and suggests that common processes may motivate the experience of structure in speech and music, noting the association between phonological and entrainment capacities in children, while Marc Leman argues that the notion of entrainment should be broadened so as to incorporate a spatiotemporal dimension rooted in bodily gestures.

In Meaning, Philip Barnard presents a multi-layered model of meaning in mind, incorporating two distinct forms of meaning: propositional meaning, and implicational meanings, the latter encapsulating a blend of abstract (conceptual) and holistic (affective, embodied) significances. He situates the model in evolutionary context, and notes that it can provide a means of accounting for the range of types of meaning that have been attributed to music and to language. Marcel Zentner follows a different route in providing a holistic approach to characterising meaning in language and music, arguing that rather than being ineffable, music's meanings may in fact be susceptible to linguistic representation. Uli Reich, by contrast, suggests that a fuller taxonomy of types of meaning than is considered by Barnard or Zentner is required to characterise meaning as manifested in linguistic and in musical contexts.

In Meaning in culture, Richard Widdess takes culture as the matrix of meaning, particularly musical meaning. Starting from Bloch's accounts of the idea of cultural knowledge and its dynamics, he provides three quite disparate instances of meaning-relations emerging from different facets of the embedding of musical praxis in cultural contexts, arguing that these meaning-relations exemplify foundational cultural schemas that are proper to different cultures. Ian Cross distinguishes between intracultural and supracultural processes in attempting to characterise how music can appear endowed with meaning, while Jerome Lewis proposes that a driving motor of culture is aesthetic orientation, and that music's capacity to embody such aspects of foundational cultural schemas provides it with a singular power to illuminate "the collective tacit knowledge that we call culture".

We are grateful to Peter Keller for having encouraged this submission to Empirical Musicology Review. The series of meetings underlying this special issue has been funded by the British Psychological Society (grant for the programme winning the Research Seminar Competition 2009-10). The substantial contribution of Middlesex University and the University of Cambridge is also gratefully acknowledged. Many thanks to Sarah Hawkins (Cambridge) for having facilitated some crucial invitations and to Simone 
Falk (Munich) for her scientific committee work. Besides the main speakers, we would like to thank chairs, workshop leaders and discussants as well as all participants and contributors for lively presentations, comments, questions and posters, all of which have created a very fertile ground for discussion during the seminars. The local organizers and the support structures have contributed to the success of the event, and special thanks must go to students and research assistants who helped with a myriad of tasks, from manning the registration desk to helping attendees and presenters in orientation and technical issues.

\section{END NOTES}

[1] For further information and abstracts of each seminar see:

http://www.mdx.ac.uk/research/areas/psychology/language/music/index.aspx

\section{REFERENCES}

Blacking, J. (1976). How Musical is Man? London: Faber.

Cross, I., \& Woodruff, G. (2009). Music as a communicative medium. In R. Botha \& C. Knight (Eds), The Prehistory of Language. Oxford: Oxford University Press, pp. 77-98.

Darwin, C. (1871). The descent of man and selection in relation to sex. London: John Murray.

Deutsch, D., Henthorn, T., \& Lapidis, R. (2011). Illusory transformation from speech to song. Journal of the Acoustical Society of America, Vol. 129, pp. 2245-2252

Franco, F., Brunswick, N., \& de Mornay-Davies, P. (2010). Research seminars on music \& language. The Psychologist, Vol.23, No. 11, pp. 913-914.

Rebuschat, P., Rohrmeier, M., Hawkins, J.A., \& Ian Cross, I. (Eds) (2012). Language and Music As Cognitive Systems. Oxford: Oxford University Press.

Slevc, L.R. (2012). Language and music: sound, structure, and meaning. WIREs Cognitive Science, Vol. 3, pp. 483-492. 